\title{
Formador de leitores, formador de professores: a trajetória de Max Butlen
}

Belmira Oliveira Bueno'

Neide Luzia de Rezende'

I- Universidade de São Paulo, São

\section{Resumo}

Nesta entrevista, Max Butlen, amplamente conhecido por seu trabalho no campo da leitura, da formação de leitores e de professores, traça um percurso de sua trajetória e desenvolve uma discussão rica a partir das contribuições teóricas assentadas em uma longa vivência na escola pública, que o tornaram referência em dois temas dentre os mais desafiadores para a escola nos dias de hoje: o ensino da cultura da escrita e a profissionalização dos professores. Na França, foi sucessivamente professor em diferentes instituições de formação de professores, junto ao Ministério da Educação e o da Cultura, onde, em funções e cargos múltiplos, fez sobressair seu trabalho em prol da atualização das práticas escolares de leitura e da configuração e uso das bibliotecas públicas e escolares. Sua tese de doutorado em ciências da educação, Les politiques de lecture et leurs acteurs, 1980-2000, defendida na Universidade de Paris 5, reúne esses dois campos de saberes universitários e da ação profissional e mostra a centralidade que as questões da leitura assumem na França nos finais do século XX. No Brasil, ele trabalhou junto ao Ministério da Educação, de 1994 a 1998, ampliando, desde então, sua colaboração com grupos de pesquisadores de vários estados, para tratar seja das temáticas da leitura seja daquelas referidas à universitarização dos professores. Desenvolve também, a partir de suas experiências em ambos os países, comparações profícuas no que se refere a procedimentos de formação de professores e ao comportamento intelectual dos jovens diante das novas tecnologias e das mudanças sociais.

\section{Palavras-chave}

Leitura - Formação de leitores e professores - Universitarização Profissionalização - França-Brasil

Paulo, SP, Brasil.

Contatos: bbueno@usp.br;

neirez@usp.br 


\section{From the education of readers to the education of teachers: an interview with Max Butlen}

Belmira Oliveira Bueno'

Neide Luzia de Rezendel

I- Universidade de São Paulo,

São Paulo, SP, Brasil.

Contatos: bbueno@usp.br;

neirez@usp.br

\section{Abstract}

In this interview, Max Butlen, widely recognized for his work in the areas of reading, reader education and teacher education, outlines his trajectory and offers a fruitful discussion based on his theoretical contributions, grounded in a long experience in public schools, which turned him into a reference in two of the most challenging themes for the school today: the teaching of the culture of writing, and the professionalization of teachers. In France, he worked in various teacher education institutions and with the Ministries for Education and Culture, where, in multiple posts and functions, his work in favor of the renewal of school reading practices and of the configuration and use of public and school libraries gained visibility. His doctorate thesis in the Sciences of Education, Les politiques de lecture et leurs acteurs, 1980-2000, presented to the University of Paris V, brings together these two fields of academic knowledge and professional activity, and demonstrates the centrality that the issues of reading have taken in France in the late 20th century. In Brazil, he worked with the Ministry for Education and Culture from 1994 to 1998, afterwards expanding his collaboration to groups of researchers from various states, both in themes related to reading and to the process of teacher universitization. Based on his experience in both countries, he also makes fertile comparisons regarding the procedures of teacher education, and the intellectual behavior of youngsters when faced with the new technologies and social transformations.

\section{Keywords}

Reading - Education of readers and of teachers - Universitization Professionalization - France-Brazil 


\section{Apresentação}

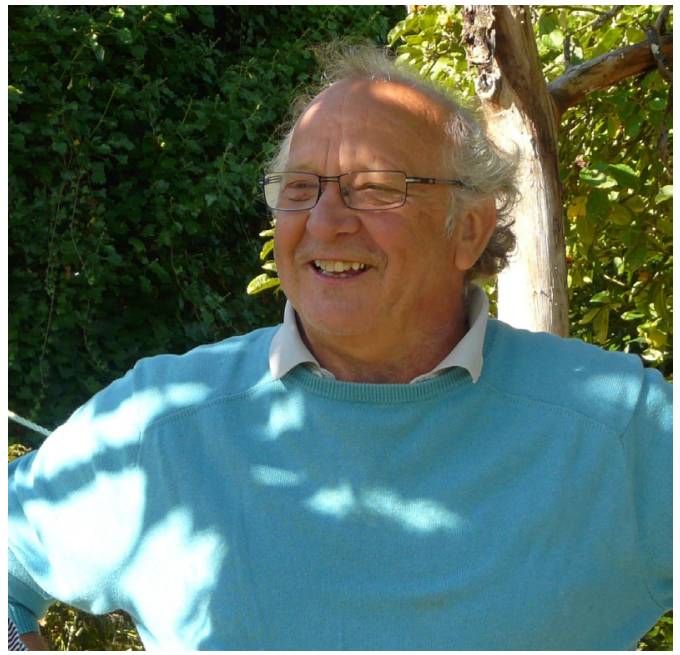

Fonte: arquivos do entrevistado

Max Butlen é conhecido por seu trabalho no campo da leitura, da formação de leitores e de professores. Suas contribuições teóricas, assentadas em uma longa vivência na escola pública, tornaram-no referência obrigatória em dois temas dentre os mais desafiadores para a escola nos dias de hoje: o ensino da cultura da escrita e a profissionalização dos professores. A presente entrevista dá a conhecer seu percurso na área da leitura e no campo da educação, da formação e da pesquisa. Ao mesmo tempo, fornece informações e reflexões preciosas sobre o processo de constituição dos formadores de professores na França desde a década de 1970, época de grandes mudanças tanto para essa área quanto para as políticas, práticas e teorias sobre a leitura.

Ele foi sucessivamente professor em diferentes instituições de formação de professores, junto ao Ministério da Educação e o da Cultura. Seus cargos e funções foram múltiplos nessas instituições francesas, nas quais se destaca seu trabalho em prol da atualização das práticas escolares de leitura e da configuração e uso das bibliotecas públicas e escolares. Sua tese de doutorado em ciências da educação, Les politiques de lecture et leurs acteurs, 1980-2000, defendida na Universidade de Paris 5, reúne esses dois campos de saberes universitários e da ação profissional e mostra a centralidade que as questões da leitura assumem na França nos finais do século XX (BUTLEN, 2008).

Particularmente a questão das políticas de leitura e do acesso à informação o trouxe ao Brasil por diversas vezes (BUTLEN, 1995). De início, trabalhou como assessor do Ministério da Educação por quatro anos, de 1994 a 1998, período em que visitou e assessorou múltiplas universidades, incluindo a Universidade de São Paulo (USP), a Universidade Estadual de Campinas (Unicamp), a Universidade Estadual Paulista (UNESP) e a Pontifícia Universidade Católica (PUC) do Rio Grande do Sul e de Minas Gerais. Sua cooperação com o Brasil tem se ampliado também com a recepção na França de doutorandos e doutores brasileiros, principalmente da USP e da UNESP. Esses vínculos não se deram por acaso: as intervenções de Max Butlen no campo educacional tocam em pontos centrais do processo de escolarização, ao abordar os desafios da formação de um leitor polivalente e da construção de uma cultura literária ao longo do ensino básico, desde a escola maternal, de modo a favorecer a constituição de uma cultura comum.

Tendo trabalhado como professor de alunos de meios sociais desfavorecidos, em colégio da periferia parisiense, desenvolveu a forte convicção de que esse desafıo só poderia ser enfrentado se a formação dos professores estivesse igualmente contemplada nessa perspectiva, a qual não diz respeito apenas à formação dos professores de língua materna, visto considerar que todos os docentes acham-se envolvidos com a formação de leitores. Nesse elo reside a originalidade de seu pensamento, cujo direcionamento às práticas de formação de professores se tornou cada vez mais intenso, sobretudo a partir da implantação dos Instituts Universitaires de Formation de Maîtres (IUFM) no final dos anos 1980, que buscavam unificar a formação dos professores na França. 
Os IUFM sofreram resistências políticas e instigaram grandes polêmicas teóricas, o que contribuiu para torná-los terreno fértil para o desenvolvimento de pesquisas e de práticas inovadoras de formação. A partir de 2009, tais polêmicas se reacenderam, dessa vez devido à inclusão obrigatória do mestrado profissional no curso de formação de professores, em obediência às diretrizes da União Europeia. Na época, como diretor adjunto do IUFM de Versailles na Universidade de Cergy-Pontoise, Max Butlen coordenou a criação do mestrado "Ofícios do ensino, da educação e da formação", que respondia ao conjunto dos percursos de formação dos futuros professores e também dos responsáveis pelos setores educativos e culturais. Nesse âmbito, ele impulsionou particularmente a criação de duas especialidades de mestrado: de um lado, a especialidade "formação de formadores", que preparava para o trabalho de formação de professores e de outros profissionais; de outro lado, a especialidade "literatura juvenil, preparação ao trabalho do livro e da leitura para o público jovem". 0 curto lapso de tempo transcorrido desde o início da masterização e da criação, em 2013, das Écoles Supérieures du Professorat et de l'Éducation (ESPE), que vieram a substituir os IUFM, ainda não permite avaliar o êxito dessa experiência. Todavia, não há dúvida de que essas mudanças marcam uma nova etapa na política de universitarização e profissionalização dos professores na França ${ }^{1}$.

Ora, todas essas experiências são de grande importância para o Brasil, uma vez que tanto educadores como pesquisadores sempre nutriram interesse pelas experiências pedagógicas francesas e seus modelos de formação docente. A perspectiva comparada

1- 0 termo universitarisation (aqui traduzido por universitarização, no seu uso recente em português) foi cunhado por Bourdoncle (1997, 2000), para se referir ao processo de transferência da formação dos professores primários para as universidades, antes feita pelas Escolas Normais. Similarmente, o termo masterisation (traduzido aqui por masterização) generalizou-se a partir das discussões que ocorreram no sistema de formação de professores na França, com a obrigatoriedade do mestrado profissional (master). Para maiores detalhes, ver: Chartier e Butlen (2006), Bello e Bueno (2012), Sarti (2013), dentre outros. é oportuna para aguçar nossos olhares e nos conduzir a uma maior compreensão dos objetos de pesquisa, das políticas educacionais, das práticas escolares. Por exemplo, sobre as diferenças que marcam as concepções e as políticas de universitarização e profissionalização dos professores na França e no Brasil. De que modo essas experiências podem se iluminar mutuamente, quais desafios apresentam? Eis uma das indagações que orientaram a condução da presente entrevista, visando a explorar as potencialidades da experiência que Max Butlen acumulou na França e em suas estadias no Brasil.

No segundo semestre de 2013, ele trabalhou na Faculdade de Educação como professor visitante da USP, retornando em abril de 2014. Nessas ocasiões, ministrou, em parceria com docentes da FEUSP e da UNESP, três cursos de pós-graduação: Leitura no século XXI: políticas, espaços de formação, abordagens e avaliação; Modelos contemporâneos de formação e profissionalização docente: Brasil e França; e Instâncias de constituição de leitores - as mediações na família, escola, biblioteca/ sala de leitura em meios impressos e digitais. Sínteses do trabalho que vem desenvolvendo (BUTLEN, 2012; 2015), os conteúdos abordados por ele ajudam a repensar aspectos importantes da formação docente e da formação de leitores.

Por meio da análise comparativa, mostrou que, no contexto francês, houve, num primeiro período, a busca de um processo de profissionalização do ensino superior nos IUFM por meio da construção da figura original do formador, enquanto no Brasil a ênfase tem recaído, a partir de 1996, sobre a universitarização dos professores das séries iniciais do ensino fundamental. Essa diferença decorre das relações estreitas que os profissionais dos IUFM desenvolveram com os formadores "du terrain" 2 favorecendo uma troca intensa

2- São chamados "formateurs du terrain professionnel" os professores que se tornaram formadores após ter passado por um exame de 
de saberes entre o campo da pesquisa e o da prática. Essa relação é ainda tênue no Brasil, razão pela qual a universitarização se encontra mais referida à titulação em nível superior. No que diz respeito à cultura letrada, os conceitos trazidos por ele ajudam igualmente a repensar vários aspectos, em especial a transformação das bibliotecas públicas (e escolares) em decorrência das novas práticas de leitura. As bibliotecas francesas desde o século XIX vinculavam-se a uma tradição de conservação e não a uma dinâmica de difusão, o que definia toda uma configuração - arquitetura, espaço, gestão das coleções, formação de pessoal - pensada e organizada para servir essencialmente a práticas letradas e eruditas (de resto, também essa era a concepção nas bibliotecas brasileiras, que adotavam modelos culturais franceses), enquanto, nas escolas, a leitura concentrava-se numa seleção de textos do cânone. Butlen (2008) denominou essa biblioteca tradicional como Templo do Saber e essa prática de leitura como intensiva. A emergência e desenvolvimento paulatino de um novo modelo - Tous les livres pour tous les lecteurs [Todos os livros para todos os leitores] - ao longo do século XX promoveram o aparecimento de bibliotecas modernas, multimídias, com livre acesso, a serviço de todo tipo de leitor, as quais se multiplicaram nas últimas décadas, de modo a que a oferta pública de leitura correspondesse às evoluções das práticas sociais e culturais e às exigências

qualificação específico. Muitos deles dividem seu tempo de trabalho entre a sala de aula de uma escola, as atividades de formação nos IUFM / ESPE e 0 acompanhamento profissional dos professores iniciantes. populares de distração, instrução e orientações (leitura extensiva).

Como conclui na entrevista, tais desenvolvimentos não foram, todavia, suficientes para alterar o paradigma de ensino tradicional da literatura, mesmo na França. Entretanto, com o advento de novas teorias sobre recepção, sobre o papel do leitor, discutido em vários campos da área de humanas, com o consenso sobre a necessidade de melhoria da oferta de leitura a partir dos anos 1980 e a inserção dessa questão nas propostas educacionais, a escola é colocada mais uma vez na berlinda e instada a transformar suas ações e resultados em prol da formação de leitores. Max Butlen confia na escola e na contribuição que ela pode oferecer para que cada aluno tenha melhores perspectivas, mas acredita também que, por conta própria, ela não será capaz de impor transformações radicais na estrutura e relações sociais.

Tendo em vista o acesso à tecnologia digital e o afastamento da leitura nos moldes convencionais impressos, no contexto de ambos os países, Butlen aponta para a necessidade da construção de pontes entre as modalidades de cultura, de modo a repensar e recriar as didáticas da leitura literária, ao mesmo tempo em que se coloca, evidentemente, o trabalho necessário do formador de professores e do formador de leitor. Trata-se, como ele sublinha, de um caminho cheio de pedras, tanto numa situação de excelentes aportes teóricos e de políticas públicas consequentes (ainda que muitas vezes criticadas por ele), quanto naquela de um país como o Brasil, que há pouco começou a se atualizar nesses campos.

\section{Referências}

BELLO, Isabel Melero; BUENO, Belmira Oliveira. Programas especiales de formación superior de profesores en Brasil: la universitarización del magisterio en cuestión. Archivos Analíticos de Políticas Educativas, v. 20, n. 6, feb. 2012. Dispnível em: <http://epaa.asu.edu/ojs/article/view/968>. Acesso em: 2014.

BOURDONCLE, Raymond. Normalisation, academisation, universitarisation, partenariat: de la diversité des voies vers l'université. Revista da Faculdade de Educação, São Paulo, v. 23, n. 1/2, p. 29-48, jan./dez. 1997. 
BOURDONCLE, Raymond. Professionnalisation, formes e dispositifs. Recherche et Formation, Lyon, n. 35, p. 117-132, 2000.

BUTLEN, Max. Compreensão e interpretação literárias: duplo risco da escola ao liceu. Leitura: Teoria e Prática, Campinas, n. 58, jan.jjun. 2012.

BUTLEN, Max. 0 desafio da participação dos profissionais de campo na formação docente. São Paulo: Unesp, 2015. № prelo.

BUTLEN, Max. Les politiques de lecture et leurs acteurs - 1980-2000. Lyon: Institut National de Recherche Pédagogique, 2008. $614 \mathrm{p}$.

BUTLEN, Max. Proposta para uma política de leitura. Boletim da Associação Internacional de Leitura Conselho Brasil Sul (ALBS). International Reading Association (IRA), Porto Alegre, n. 1-2, p 3-17, 1995.

CHARTIER, Anne-Marie; BUTLEN, Max. L'analyse de pratiques: rétrospectives et questions actuelles. Recherche et Formation, Lyon, n. 51, p. 11-25, 2006.

SARTI, Flavia Medeiros. Pelos caminhos da universitarização: reflexões a partir da masterização dos IUFM franceses. Educação em Revista, Belo Horizonte, v. 29, n. 4, p. 215-244, dez. 2013. 


\section{Formador de leitores, formador de professores: a trajetória de Max Butlen.}

Para iniciar, gostariamos que você nos contasse como foi sua formação e como nasceu seu interesse pelas questões da leitura e da formação de professores.

Fui formado numa época em que o sistema de formação era muito diferente do que é hoje, do ponto de vista da profissionalização e, mais ainda, da universitarização. Entrei na École Normale d'Instituteurs (ENI) após o ensino fundamental II, aos 16 anos. As ENI possuíam a reputação de funcionar como um tipo de elevador social, uma vez que os bons alunos dos meios populares eram selecionados ao final do ensino secundário para ali continuarem seus estudos. Isso se dava graças a um sistema de bolsas oferecidas mediante um concurso altamente concorrido. Como contrapartida, exigia-se que os alunos selecionados assinassem um contrato com o compromisso de servir ao Estado e à educação nacional por dez anos. Esse foi o meu caso. Após o baccalauréat (equivalente do Exame Nacional de Ensino Médio - ENEM), ao invés de começar a formação profissional de um ano para trabalhar como instituteur [professor do ensino fundamental I] nas escolas básicas, tive a chance de entrar na universidade como aluno de Letras, graças a uma segunda bolsa, cuja seleção ocorreu no seio da ENI de Paris. Ao final do primeiro ano universitário, tendo sido aprovado num concurso para o instituto de preparação para o ensino do segundo grau, passei a receber um salário muito bom, que me permitiu preparar tranquilamente o bacharelado na Sorbonne e, além disso, o concurso final de recrutamento de professores do colégio [ensino fundamental II] e do liceu [ensino médio].

Os bons alunos provenientes de meios populares encontram ainda hoje condições de concorrer para a progressão nos estudos e na carreira, tal como ocorreu em sua época?

Minha história pessoal é bem representativa do percurso de muitos alunos dos meios populares que conseguiram fazer seus estudos na época. De fato, as Escolas Normais garantiam essas funções de acompanhamento, formação e promoção, possibilidades que quase já não existem depois da criação dos Instituts Universitaires de Formation de Maître (IUFM). Desse ponto de vista, pode-se notar que o processo de universitarização, mesmo sendo útil e necessário, teve como consequência indireta afastar da carreira do ensino muitos alunos oriundos de meios desfavorecidos, uma vez que já não são oferecidas bolsas suficientes que lhes permitam levar a cabo estudos mais longos. Assim, contrariamente ao que se observa no Brasil, a distância social e cultural entre os novos professores e os alunos se agudiza hoje na França.

Em que momento desse percurso você identifica seu interesse pelas questões da leitura e se direciona para essa área?

Eu sempre quis me tornar professor, mas, de início, não sabia exatamente em que área poderia atuar. Já tínhamos na família várias disciplinas “ocupadas" por meus vários irmãos. Então, pensei "vou fazer Letras, já que sempre gostei muito de ler". Sou leitor desde os 9-10 anos, e isso se deu por influência dos padres. $\mathrm{Eu}$ pertencia à igreja católica, frequentava as colônias de férias dos padres, gostava de ler as histórias de vida dos santos, mas também de jogadores de futebol. Descobri a leitura desse modo e pouco a pouco me apaixonei por essa atividade. Em casa, tínhamos poucos livros, mas meus pais me incentivavam, apesar de seu distanciamento da cultura escolar. Eles tinham fortes valores educacionais e meus irmãos colocavam seus livros à minha disposição. Alguns professores também me estimularam.

Em que momento você começou a dar aula, a ser professor?

Após ter sido aprovado no concurso de recrutamento de professores de letras modernas, que era muito difícil na época, fui nomeado em primeiro lugar para um colégio da periferia 
parisiense, numa zona de educação prioritária, onde dei aula para alunos de 12 a 16 anos. Foi quase um choque, pois encontrei um colégio muito diferente daquele que havia cursado em minha juventude. Descobri, então, problemas de aprendizagem da língua e da literatura para os quais a Sorbonne não havia absolutamente me preparado. Isso foi em 1972-73, exatamente no momento em que ocorria na França uma grande massificação do ensino primário e secundário. Foi um momento marcado pela concentração de muitos imigrantes na periferia parisiense, um período de muita transformação no país. 0 trabalho do professor tornou-se outro, uma vez que o colégio passou a ser frequentado por jovens muito distantes da cultura erudita, legítima. Ao desembarcar nessa periferia, dei-me conta de que não se tratava apenas de ensinar a leitura literária aos herdeiros descritos por Bourdieu. Houve um aumento do número de alunos fracos na área da leitura e da escrita. Entretanto, essas crianças me proporcionaram um aprendizado profissional surpreendente. Como os outros professores, a formação acadêmica que recebi foi inteiramente clássica, letrada. Nas salas dos professores da escola em que fui ensinar, podiase ouvir comentários assim: "Gente, viram essas crianças que recebemos este ano? Nunca vimos isso! Não sabem ler, não podemos fazer nada com eles!". Esse tipo de discurso era recorrente, na medida em que os professores não estavam preparados para aquela nova tarefa. Aqui começou meu interesse pela formação de leitores e de professores. Fundamentalmente, eu assim indagava: se os alunos de 14-15 anos não sabem ler, qual deve ser a nossa tarefa como professores? Não seria ensiná-los a ler? Fui, então, em busca de conhecimentos sobre como formar um leitor, como aprender a ler, como introduzir alunos fracos no aprendizado da cultura escrita. Esses alunos se encontravam no nível que no Brasil corresponde ao $5^{\circ}$. ano do ensino fundamental, mas havia também alunos com tais dificuldades em séries mais avançadas. Procurei leituras e pesquisas sobre a formação de professores na área da leitura, passei a trocar ideias com outros profissionais e a me interrogar sobre a oferta de leitura que se fazia aos jovens. Descobrindo a literatura infanto-juvenil, conjecturei a possibilidade de fazer uma oferta pedagógica de leitura diferente, mais bem ajustada à idade e aos interesses dos alunos. Entendi que era preciso reconsiderar simultaneamente a oferta de leitura, a natureza e as formas de mediação para permitir a entrada na cultura escrita. Percebi que, no trabalho de ensino da leitura, era necessário levar em conta as práticas culturais efetivas das crianças e adolescentes, sem menosprezálas, para tentar alargá-las. Interessei-me tanto pelas técnicas da alfabetização e do letramento como pela oferta de literatura infanto-juvenil articulada à descoberta do patrimônio cultural. Com isso, comecei também a me interessar pela problemática da formação de professores.

\section{E qual foi o resultado desse trabalho com os alunos?}

Acho que consegui alguns bons resultados na formação de leitores, sobretudo para torná-los mais interessados e mais eficientes na leitura. Esse trabalho acabou despertando o interesse de alguns responsáveis pela formação docente. Fui convidado, então, para atuar na área da formação de futuros docentes para as escolas primárias [fundamental I] e também para trabalhar na formação dos futuros professores [fundamental II e ensino médio] de Letras. Desse modo, entrei na esfera da formação inicial e continuada. Saí do ensino das Letras para me consagrar inteiramente à formação, como professor da Escola Normal. Passei, assim, de professor a formador de professores.

\section{Como foi o seu percurso nessa nova tarefa de formação?}

Foi bem ligado a um desejo de eficiência profissional na formação. Após dez anos de ensino em zona de educação prioritária, eu tinha sempre em mente as dificuldades de leitura e domínio da língua por parte dos alunos da minha antiga escola 
da periferia. Então, nos anos 1980, decidi voltar à universidade (Paris 7) para fazer um duplo mestrado, em literatura e em didática das Letras. Trabalhei especialmente sobre as práticas de leitura dos adultos, confrontadas com as práticas de leitura dos jovens e com os livros da literatura infanto-juvenil. Ao mesmo tempo, comecei a participar de diversos grupos de pesquisa: no Institut National de Recherche Pédagogique (INRP), sobre as práticas de ensino; na Sorbonne, sobre a literatura juvenil; no Centre Régional de Documentation Pédagogique, sobre as bibliotecas escolares. Isso tudo me permitiu adotar uma postura mais reflexiva em relação a minhas experiências profissionais e ter acesso a novos saberes. Realmente, quanto mais eu me formava, mais se alargava meu trabalho de formador e mais eu sentia a necessidade de me ligar à pesquisa. Comecei a trabalhar com Jean Hébrard e Anne-Marie Chartier e também com outros pesquisadores, linguistas, estudiosos da literatura, psicolinguistas, sociólogos, na área da leitura e da escrita, bem como das bibliotecas. Nos anos 1980, cresceu a necessidade de analisar, repensar e nortear as políticas de leitura e as políticas de formação dos leitores, o que veio a constituir meu eixo de pesquisa. Enquanto as coisas evoluíam assim, fui convidado a organizar formações locais e depois regionais para os professores e bibliotecários de meu departamento e da região parisiense, sobre a leitura, a literatura, o acesso à informação, as bibliotecas, o ensino da língua. Depois, dirigi estágios nacionais voltados para professores formadores nas ENI, nos IUFM, e também para inspetores e conselheiros pedagógicos. Durante esses encontros, compreendi a importância de conjugar formação e pesquisa, de desenvolver um trabalho teórico enraizado no terreno escolar. Tendo estabelecido relações com inúmeros profissionais, formadores e pesquisadores do campo, percebi que dispúnhamos de poucos meios de comunicação entre nós. Nenhuma revista propunha um espaço de pesquisa ao conjunto desses atores e a seus parceiros. Assim, em 1987, planejei a criação da Argos, uma revista dedicada à cultura da escrita, ensino da língua e uso das bibliotecas. 0 objetivo era confrontar e articular a análise das experiências da prática com as propostas de pes- quisa e formação. Tratava-se de oferecer a todos os atores envolvidos um espaço de diálogo, de troca, e de abrir a revista aos parceiros do mundo da leitura e da escrita - bibliotecários, autores, editores, responsáveis pelas políticas de leitura. A revista funcionou durante 26 anos, de início, caracterizando-se como uma revista profissional, parisiense, que adquiriu depois uma abrangência nacional, tendo mesmo uma dimensão internacional. Em razão desse conjunto de atividades e de experiências, fui chamado em 1991 pelo Ministério da Educação para cuidar do Plano Nacional de Leitura, Biblioteca, Domínio da Língua. Trabalhei com Jean Hébrard, que se tornou, na época, conselheiro especial do ministro Jack Lang. Foi uma época de mudanças relativamente importantes que, a meu ver, marcou uma ruptura.

Como você situa essa ruptura? No prazo de uma década, deu para perceber uma mudança, uma ruptura, em relação aos paradigmas anteriores de formação?

Acho que a ruptura ocorreu nos anos 1990, mas os efeitos foram sentidos bem depois, até hoje, não sem contradição e, mesmo, sem retrocesso. Nessa década, ocorreram profundas transformações. Após o desaparecimento das escolas normais, a formação dos professores e a formação dos leitores se afastaram de uma concepção militante, intuitiva, para se profissionalizar, se racionalizar e se universitarizar. Logicamente, as resistências foram muitas e esse movimento está ainda em curso. Aprendi que as mudanças na esfera pedagógica demoram sempre muito para se realizar.

\section{Foi nessa época que você veio para o Brasil? 0} que o motivou a vir para cá?

Eu vim para o Brasil em 1994. Em 1993, houve uma mudança no governo francês. Deixei o cargo no Ministério da Educação. Durante o ano anterior, tivera a oportunidade de conhecer e receber em Paris a professora 
Magda Soares, da Universidade Federal de Minas Gerais (UFMG), que fora convidada pelo ministério francês para uma estadia de estudo sobre nosso sistema. Foi meu primeiro encontro com o Brasil e os brasileiros. Depois, recebi uma proposta do Ministério das Relações Exteriores para trabalhar no Brasil como consultor na Secretaria de Educação Fundamental, para dar continuidade ao Pró-Leitura, um programa que já existia desde 1991, iniciado por Elie Bajard. Trabalhei quatro anos junto ao MEC como consultor para essa proposta, que visava a melhorar a formação de leitores e a formação dos professores. Considerei muito interessante essa ideia de pensar a transformação da formação de professores a partir da entrada de um conteúdo de formação: a cultura da escrita.

\section{Em que instância isso se dava? Você tinha um grupo no MEC?}

No MEC, havia um pequeno grupo de assessores do programa com professores da UFMG, USP, Rio Grande do Sul, Recife, Salvador e Natal. Era o comitê científico que animamos e dinamizamos. Em Brasília, contávamos com o apoio de um núcleo de pessoas que, no início, eram coordenadas por Margarida Cavalcante e, depois, por Cinara Dias Custódio. Paulo Renato era ministro. Tínhamos também correspondentes em vinte estados, junto às secretarias de educação. Foi um período muito rico, apaixonante para eu descobrir o Brasil, sob muitos pontos de vista - social, geográfico, cultural - e singularmente aprender como as coisas acontecem aqui na área da leitura, da formação dos professores e na pesquisa. Descobri o Brasil pelo prisma da leitura e da formação docente. Havia, nessa época, muita discussão a respeito da elaboração dos Parâmetros Curriculares Nacionais (PCN), cujas orientações teóricas eram muito interessantes. Só que os professores pareciam não entendê-las e houve dificuldade na recepção daquelas ótimas ideias. Essa apropriação dos PCN pelos professores supunha um importante trabalho de formação e de mediação.
Como essa experiência do Pró-Leitura se disseminou pelo país?

Em cada estado implicado, o desenvolvimento do projeto ficou sob a responsabilidade da Secretaria da Educação, que nomeou uma equipe encarregada de impulsionar o projeto. Havia lugares-piloto, experimentais, e momentos de formação, dispositivos de circulação, de difusão e informação. Produzimos um texto de orientação intitulado "Pró-Leitura na formação de professores”. Havia encontros técnicos nacionais e locais. 0 comitê científico dava assessoria nos diversos estados participantes. Além disso, o projeto comportava também estágios de estudo, o que favorecia a organização de intercâmbio de formadores e pesquisadores entre os dois países. Na época, uma concepção política global para a formação tanto dos professores como dos alunos estava em obra. 0 Pró-Leitura correspondia a um espaço de reflexão entre outros, num país em busca de mudança e melhoria em todos os aspectos. Percebi os grandes avanços do país nas taxas de alfabetização e, com a lei Darcy Ribeiro, um movimento impressionante de universitarização docente. 0 contexto brasileiro era muito diferente do francês, e era interessante notar as variações nas formas adquiridas pela universitarização e pela profissionalização, comparar as estratégias e as vontades políticas tanto para a leitura quanto para a formação docente. De um lado, um processo aparentemente muito centralizado (na França); de outro, políticas aparentemente muito diversificadas (Brasil). Portanto, grandes diferenças de contexto e de história. Mas pude observar também algumas semelhanças, preocupantes às vezes, mesmo que os problemas não tivessem exatamente as mesmas causas nem as mesmas escalas. Penso em especial em uma tendência social de desvalorização do trabalho dos professores, o que justificaria redobrar os esforços nos dois casos. Observei também um sistema de ensino público em dificuldade, questionado e criticado por todos, no momento em que os dispositivos de avaliação começavam 
a se generalizar. Nos dois países, muitas críticas dos resultados da escola no campo de formação de leitores, justo quando a internet se anunciava e gerava evoluções consideráveis e convergentes nas práticas de leitura dos jovens nesse fim de século XX. No final das contas, o Pró-Leitura conseguiu se integrar a uma política mais abrangente de formação de professores. Voltei a Paris em 1998. A partir dessa época, tive a oportunidade e a sorte de continuar a participar, e a organizar, muitos intercâmbios entre pesquisadores, formadores e instituições franco-brasileiras.

\section{E como foi seu retorno à França. Lá o panorama já era outro?}

Ao retornar à França em 1998, os IUFM já estavam bem instalados. De certa forma, tive que recomeçar minha carreira, pois, ao sair do país, perdi meu posto. Precisei me concursar novamente para ser recrutado por um IUFM, tendo sido admitido pelo IUFM da Academia de Versailles. Propus-me então a fazer o doutorado, já que antes não tivera tempo para fazê-lo. Mas também havia outra razão: no tempo das escolas normais, não se exigia o título de doutorado para assumir a função de professor formador; a primeira condição era passar pelo concurso de recrutamento de professor do ensino médio. Com a criação dos IUFM em 1990, e a emergência dos desafios da profissionalização e da universitarização, as coisas mudaram, o que criou problemas para alguns colegas. A falta de um diploma de pesquisador foi a origem de muitas dificuldades para a inserção deles no ensino superior. Raymond Bourdoncle observou que a universitarização da formação de professores provocou rupturas às vezes dolorosas para o antigo pessoal das ENI e dos IUFM. Eu fiz parte dos formadores que tentaram ultrapassar essas dificuldades e rupturas, aceitando completar sua formação universitária após ter vivido um processo de profissionalização como formadores nas escolas normais. Então, fız o doutorado sobre as políticas de leitura e seus atores no final do século XX. Quando acabei esse trabalho, ganhei o título de maître de conférences das universidades. Depois fui chamado pelo INRP para dirigir, com Anne-Marie Chartier, a missão Pesquisa e Formação. Dois anos depois, fui designado diretor adjunto do INRP, na função de diretor de pesquisa. Isso perdurou até a chegada de um ministro que pretendeu ditar aos pesquisadores da área da leitura os resultados de suas pesquisas. Voltei ao IUFM de Versailles e lá assumi a função de diretor adjunto.

Como se deu a unificação do sistema de formação de professores com a criação dos IUFM, diante das resistências vindas de vários setores, incluindo o próprio professorado?

Foi uma luta permeada por muitas tensões. Na história da formação docente na França, sempre houve briga entre vários campos. Para simplificar, destaco aqui dois deles. 0 primeiro campo reúne aqueles que (desde o século XIX) consideram que, para se tornar professor, não é necessária uma formação de alto nível acadêmico. 0 segundo campo reúne aqueles que, inversamente, consideram que ensinar é algo tão complexo que demanda um alto nível teórico e prático, necessário para adquirir saberes acadêmicos e saberes profissionais. Entre as outras tensões, podemos destacar também o choque de cultura que ocorreu quando docentes das duas tradições passaram a conviver, pela primeira vez, no mesmo instituto de formação. Na época anterior, como apontei, os professores primários, herdeiros dos instituteurs, eram formados nas escolas normais, enquanto os professores secundários, especialistas de cada disciplina, tinham, após um difícil concurso de recrutamento, uma curta formação prática num centro específico de formação. Os primeiros tinham tendência a considerar que possuíam melhor atuação do ponto de vista pedagógico e muitos estimavam que, mais importante do que os conteúdos, era a qualidade das práticas pedagógicas. Por sua vez, os segundos achavam que não precisavam de discursos sobre a 
prática, uma vez que o que importava era o domínio dos conteúdos disciplinares a ensinar. Além disso, havia uma hierarquia implícita que valorizava os professores de colégio e liceu, em detrimento dos professores primários. Nesse quadro, o desafio dos IUFM consistia em juntar esses dois grupos de professores para oferecer uma formação que tivesse, no mesmo espaço, a mesma duração e, com isso, criar uma cultura comum. Houve outras resistências, notadamente no campo político; a formação docente foi também um campo de divisão entre esquerda e direita, no qual os IUFM estavam no primeiro grupo.

Como os IUFM venceram essas resistências? É possivel afirmar que eles foram implantados mais por uma força externa do que interna?

Na verdade, não havia outra opção senão implantar os institutos, na medida em que a análise objetiva da situação do ensino dentro do contexto da mundialização, da revolução tecnológica e da massificação não permitiu outro caminho senão aquele da elevação do nível da formação docente em todos os países. Instâncias internacionais diversas, entre as quais a Organização das Nações Unidas para a Educação, a Ciência e a Cultura (UNESCO) e o Conselho Europeu, insistiam igualmente nessa mudança. Qual dirigente sério poderia dizer que não era bom elevar o nível de formação dos professores do ponto de vista acadêmico e profissional? De fato, quando a direita voltou ao poder na França, ela não suprimiu os IUFM. As forças externas sem dúvida tiveram uma forte influência, mas, inversamente, podemos dizer que o peso da França foi importante nas instâncias europeias. Houve também o rico trabalho de uma comunidade de pesquisadores francófonos.

Em relação a essas mudanças, a França tem um campo teórico muito forte, que inclusive impulsiona a reflexão fora do seu país, principalmente aqui no Brasil. As teorias sobre políticas de leitura e o campo intelectual provocaram uma mudança muito grande do ensino desde 1970. As teorias que hoje temos, mais contemporâneas, vieram no bojo dessas mudanças. Você poderia falar um pouco mais sobre esse momento?

Esse campo de construção de saberes profissionais se firmou com a participação e o encontro de três categorias de atores - a elite dos profissionais do cotidiano da sala de aula, os formadores de professores, e os pesquisadores. Graças a pesquisas e experimentações sucessivas nas ENI, nos IUFM, nas universidades, elaboraram-se, entre outros, o benefício da formação docente, o campo teórico da análise de práticas de ensino, dos estudos de caso, das situações-problema, do memorial profissional, da entrevista de explicitação, do trabalho sobre os gêneros profissionais, sobre o ajustamento dos gestos profissionais na dinâmica da aula, sobre a avaliação das competências, a gestão dos imprevistos... A respeito de todos esses tópicos, as contribuições conjugadas de pesquisadores da francofonia foram determinantes. Penso sobretudo em Marguerite Altet, Raymond Bourdoncle, Philippe Perrenoud, Léopold Paquay, Maurice Tardif, Dominique Bucheton e muitos outros. No campo da língua, encontramos igualmente uma configuração de pesquisas cruzadas de alta qualidade, como, por exemplo, aquelas de Jean-Paul Bronckart, Joaquim Dolz, Bernard Schneuwly. No caso da didática da leitura e da literatura, as propostas de Yves Reuter, Catherine Tauveron, Roland Goigoux sobre a leitura, a compreensão, a interpretação, que levaram a repensar profundamente o diálogo didático aluno-professor. Os conceitos de leitura literária, de sujeito leitor foram redefinidos por Annie Rouxel, Jean-Louis Dufays, Gérard Langlade. As pesquisas não nasceram todas nos centros de formação de professores. Todavia, os IUFM, assim como as Écoles Supérieures du Professorat et de l'Éducation (ESPE) hoje, foram e continuarão sendo, creio, caixas de ressonância bastante eficazes. 
Poderia precisar as relações entre os laboratórios universitários e a pesquisa nos IUFM e, hoje, nas ESPE?

Muitos pesquisadores das ciências da educação, das diversas didáticas das disciplinas, começaram sua carreira nos IUFM. Alguns deixaram as estruturas de formação dos professores para se dedicar completamente às atividades de pesquisa. Outros permaneceram dentro dos IUFM na qualidade de enseignants chercheurs [professores pesquisadores]. Em 2005, a decisão política de integração à universidade, e mesmo de inclusão, clarificou a situação dos IUFM, sublinhando uma etapa decisiva no processo de universitarização. Antes dessa decisão, de 1990 a 2005, considero, de acordo com Bourdoncle (2007), que se tratava de uma falsa universitarização, ou seja, de uma semiuniversitarização, na medida em que os IUFM, apesar de ligados ao ensino superior, permaneceram fora da universidade, em sua periferia, sem ter a possibilidade de fazer pesquisa própria e ter verdadeiros laboratórios. Com a criação de mestrados profissionais em 2009, a masterização representou a última etapa da universitarizaçao.

Você diria que o mestrado profissional, como etapa obrigatória da formação de professores, realiza uma universitarização mais plena?

Quero lembrar que, em 2009, estabeleceu-se que, para se tornar professor (da escola maternal ao final do ensino médio), era indispensável ter um mestrado, além do concurso de recrutamento. Com isso, iniciou-se o processo de criação de mestrados profissionais no âmbito dos IUFM, chamado de masterização. De modo sintético, pode-se dizer que as Escolas Normais promoveram um primeiro movimento de profissionalização e algumas premissas de pesquisa e que, em seguida, os IUFM promoveram pouco a pouco uma forte aproximação com a universidade e o fortalecimento da postura de pesquisa dos formadores. A história de muitos formadores já refletia essa aproximação e integração, como minha própria história. Vários formadores transformaram-se em docentes pesquisadores, mas outros não, o que criou um problema. Por outro lado, parece-me importante sublinhar que, dentro dos IUFM, ao mesmo tempo em que houve esse processo de universitarização, a profissionalização se desenvolveu. Antes da masterização, em 2009, talvez o movimento de profissionalização tenha sido mais forte do que o de universitarização. Entretanto, após 2009, paradoxalmente, houve um retrocesso, uma inversão dessa tendência, e a universitarização se tornou dominante. Em 2013, as ESPE substituíram os IUFM com o intuito de retomar e levar ainda mais adiante esse movimento de profissionalização de todos os professores. Agora, o desafio é buscar um bom equilíbrio entre ambos os processos, o de universitarização e de profissionalização.

Por que, de seu ponto de vista, a masterização se deu de modo equivocado?

Num contexto de crise europeia, essencialmente por razões orçamentárias, em nome da universitarização, da profissionalização e da masterização, foram impostas formações "rebaixadas" que, em verdade, tenderam a diminuir a profıssionalização e mesmo a afastar dos centros de formação os formadores vindos das escolas, que eram justamente aqueles que davam uma contribuição preciosa para a profissionalização. Nessa época, tivemos uma consequência inesperada: uma universitarização mal pensada, o que quer dizer um rebaixamento da profissionalização. A evolução recente se revelou caótica e muito decepcionante para muitos atores. Hoje, a questão é saber se as ESPE serão capazes de inverter esse processo. 0 novo modelo permanece em construção.

De que modo pode ser observado o papel profissionalizante dos IUFM? Como definir a função de formador de professores e as qualidades que isso supõe? 
0 sistema de formação francês dispõe de um trunfo que não existe em todos os países: a figura do formador profissional. Acho que vale a pena descrever essa fisionomia moldada lentamente nas ENI, nos IUFM e agora nas ESPE. 0 formador é um profissional experiente do ensino, que dispõe de saberes diversos - saber teórico, saber-ser, saber-fazer - construídos por meio da prática pedagógica da profissão de professor, bem como de pesquisas pessoais e coletivas, disciplinares e transdisciplinares, tanto sobre os saberes a ensinar como sobre os saberes para ensinar, segundo a distinção feita por Perrenoud. Para formar os futuros professores, esse formador constrói situações de descoberta, aprendizagem, reflexão e apropriação da cultura e das práticas da profissão. Ele também coloca à disposição informações, pode dar orientações, permite, enfım, aos futuros professores adquirir os conhecimentos indispensáveis para entrar e atuar na vida profissional. Convida a trabalhar com instrumentos de análise dos conteúdos das aulas, incentiva a refletir sobre posturas, gestos, métodos de trabalho, abordagens pedagógicas, dispositivos de avaliação, criando, desse modo, as condições de um desenvolvimento profissional e fomentando uma atividade mais autônoma, reflexiva e eficaz. Sua atuação é articulada com as pesquisas. Essa figura do formador resulta, pois, de uma longa construção.

Durante muito tempo, as tarefas de formação de professores se diferenciavam de maneira discutível. Nos centros de formação docente, encarregavam-se os professores especialistas de uma disciplina de transmitir os saberes a ensinar (os conteúdos disciplinares), enquanto os saberes da profissão, os saberes para ensinar, supunha-se que poderiam ser adquiridos por meio da observação, da imitação de colegas experientes nas escolas anexas. A evolução e a complexidade das tarefas de professores provocaram a necessidade de mudanças qualitativas de conteúdos de formação e a revisão dessa tradicional distribuição das tarefas. As posturas e as atividades dos dois tipos de profissionais se aproximaram até criar um desdobramento da figura do formador.
Por um lado, os professores das escolas anexas das ENI passaram a trabalhar mais com os professores encarregados de uma disciplina na formação docente, e gradualmente ganharam um novo estatuto, diferente daquele dos professores exemplares, ou seja, os mestres modelos a serem copiados e imitados. Tornaram-se formadores reflexivos, verdadeiros conselheiros pedagógicos, com o título de maîtres-formateurs [professores formadores], a partir do momento em que conquistaram um diploma específico que valorizou e trouxe reconhecimento de suas competências profissionais na formação. Constituíram uma elite da profissão docente, particularmente no ensino primário, e foram integrados às equipes pedagógicas das ENI e dos IUFM, onde muitas vezes continuam a ser designados formateurs de terrain $^{3}$. Alguns deixaram completamente a sala de aula para se tornarem formadores em tempo integral no IUFM, e agora nas ESPE. Por outro lado, os professores disciplinares nomeados nas ENI, e depois nos IUFM e ESPE, desejaram responder melhor às necessidades crescentes de formação. Como não era mais possível se limitar a uma mera transmissão de saberes disciplinares na formação inicial, passaram a se interessar pelas práticas de terrain. Nas salas de aula, nas escolas de aplicação dos maîtres-formateurs, observaram, experimentaram, analisaram novas abordagens didáticas. Desse modo, os professores disciplinares dos centros de formação conseguiram construir os saberes para ensinar que lhes faltavam, deles se apropriando e os teorizando. Ao longo do tempo, muitos conseguiram se transformar em formadores mais completos, conjugando os dois tipos de saberes. Consequentemente, a profissionalização foi fortalecida e enriquecida, graças à atuação complementar de ambos os formadores, sobretudo durante os estágios. Ao invés de ser uma espécie de momento de turismo profissional, o estágio passou a ser um momento-chave para a formação dos professores e para uma boa ligação teoria-prática, e universitarização-profıssionalização.

\footnotetext{
$\mathbf{3}$ - Ver nota de rodapé no. 3.
} 
Como os estágios foram estruturados no âmbito dos IUMF e nas ESPE?

Chegamos a distinguir três tipos de estágio, sendo que cada um tinha de ser cuidadosamente preparado, acompanhado e explorado por formadores de todos os tipos formadores de terrain, da universidade, ou seja, da ESPE. Os conteúdos teóricos do mestrado tiveram que se articular a essa preparação e exploração, o que constitui condição sine qua non de uma verdadeira formação. Destacamos o estágio de observação, o estágio de prática acompanhada e o estágio com responsabilidade plena. 0 primeiro permite descobrir a escola e os principais componentes da atividade profissional; o segundo é um grande momento de formação ao lado de um professor formador de terrain, que vai dar sentido ao trabalho de análise das práticas; o terceiro marca uma real entrada na profissão. As situações vividas na sala de aula alimentam o memorial profissional, no qual o futuro professor deve abordar alguma questão profissional, em debate à luz das pesquisas pedagógicas, mas, sobretudo, a partir de uma reflexão sobre a experiência pessoal adquirida durante os estágios.

Isso significa que a elevação do nível de profissionalização se deu por meio de uma articulação mais efetiva da teoria com a prática? É isso que está no âmago da ideia de profissionalização que ocorreu nos IUFM?

Profissionalização e universitarização se interpelam reciprocamente. 0 saber profissional passou a ser revisitado, aprofundado e teorizado cada vez mais segundo as regras da pesquisa, à medida que os professores dos IUFM e das escolas passaram a conviver com os pesquisadores vinculados às universidades. Mas isso não se realizou sem conflitos. A chegada desses novos atores aos IUFM - os pesquisadores com doutorado - modificou muito o contexto e a perspectiva da formação. No início, esse grupo era pequeno, ao contrário do grupo dos antigos professores das escolas normais que lá permaneceram e que era mais numeroso. Como já apontei, por um lado, só uma minoria dos antigos formadores aceitou o esforço de fazer doutorado; por outro lado, uma plena universitarização da formação docente supunha que os pesquisadores conhecessem e trabalhassem para além das realidades da profissão docente. 0 que não ocorreu espontaneamente. Então, a entrada dos pesquisadores e a convivência das três categorias foram e ainda são problemáticas. Houve e ainda há lutas de território, de poder e por reconhecimento recíproco.

Nesse caminho marcado por trocas, mas também por conflitos e resistências, é que se deu a elevação do nível de profissionalização? 0 que chamamos aqui no Brasil de universitarização é um processo muito diferente do que aconteceu na França. Lá, essa experiência chegou a provocar uma perda de qualidade na formação de professores?

$\mathrm{Na}$ verdade, para certo número de colegas da universidade, a profissionalização é malvista ou mal aceita, justamente, em nome da pureza dos saberes eruditos, saberes esses que, segundo eles, devem permanecer independentes de toda pressão externa, a fim de evitar a instrumentalização. A meu ver, a universitarização deveria elevar o nível de formação dos professores dos dois lados: do lado do domínio do saber a ensinar, do saber acadêmico-científıco, ou seja, dos conteúdos científicos de ensino relacionados à construção do conhecimento em cada disciplina; e também do lado dos saberes profissionais docentes, quer dizer, dos saberes para ensinar, relacionados à analise das realidades pedagógicas. A universidade pode e deve, daqui para a frente, contribuir com o enriquecimento desses saberes. Da força dessa articulação depende a melhoria da qualidade da formação. Por isso, não acho que o aumento do tempo de formação universitária para os professores seja 
acompanhado de uma queda de qualidade. Ao contrário, sob certas condições, é desejável que esse processo se faça em estreita relação com a profıssionalização. Infelizmente, após a integração dos IUFM com a universidade, essa dupla perspectiva começou a ser esquecida, cedendo lugar a uma masterização mal concebida. Não quero dizer que o mestrado profissional em si não seja desejável, mas, da maneira como esse processo tem sido levado a efeito, foi um grande equívoco. É por isso que hoje as ESPE têm por objetivo restabelecer a necessária qualidade dessa articulação.

Após 25 anos de experiência dos IUFM, pode-se considerar que houve uma melhoria no nível de formação dos alunos? As novas políticas de leitura repercutiram positivamente sobre a escolarização?

Essa é uma pergunta difícil de responder, mas é uma pergunta-chave, uma vez que os resultados não são totalmente positivos, justamente por causa das persistentes diferenças sociais e culturais. Há uma persistência da desigualdade, uma vez que os melhores alunos são cada vez melhores e os mais fracos continuam fracos. Então, só posso constatar que houve uma clara melhoria de resultados para os alunos bons e médios.

Então, Bourdieu tinha razão, e você foi uma exceção?

Sim. Mas o que é escandaloso na escola é quando as desigualdades se agravam. Com relação às pesquisas no campo da formação docente, como aceitar que os resultados dos alunos mais desfavorecidos continuem tão insuficientes diante da expectativa das famílias e das necessidades sociais, e apesar de todos os nossos esforços? Como se explica que nossos professores do século XXI têm, talvez, mais dificuldades do que os professores de tempos passados tiveram para lidar com os alunos mais fracos? Acredito que é o resultado de uma massificação mal conduzida, que não foi acompanhada de uma verdadeira democratização. A massificação foi planejada econômica e socialmente, mas a democratização não foi pensada, talvez não tenha sido realmente desejada. No final das contas, o nível global dos alunos progrediu em termos de aquisição da língua, mas é difícil atribuir isso a uma melhor distribuição social dos saberes; na verdade, essa relativa melhoria é, em grande parte, ligada ao prolongamento da escolarização. Hoje, muitos alunos que frequentam a escola não teriam tido a mesma possibilidade no passado. Por isso, se considerarmos o nível geral da população francesa, assim como o da brasileira, pode-se dizer que globalmente houve significativa melhoria em termos de acesso aos saberes, de uso da leitura e da escrita. Mas isso não significa que a proficiência dos alunos de 15 anos de hoje sejam aceitáveis no Brasil, assim como na França, conforme o Programme for International Student Assessment (PISA) revela. Houve melhoras, mas o nível médio alcançado pelos jovens alunos de hoje está longe do que seria necessário e esperado de um futuro cidadão do século XXI.

Nesse sentido, pode-se dizer que o que investimos em uma dada situação, em um dado grupo de alunos, acaba sendo uma gota no oceano?

Na França, bem como em outros países, se considerarmos os resultados do PISA, nossos esforços didáticos, de maneira evidente, aproveitaram os melhores alunos, incluindo um pouco daqueles que estiveram no portal do sucesso escolar, alunos de boa vontade cultural. Mas as dificuldades não se resolveram bem com os alunos fracos. É possível que as exigências e a elevação do nível de competência, as expectativas da sociedade e as necessidades de formação dos alunos sejam tão grandes hoje que as melhorias indiscutiveis efetuadas no ensino não permitem, de fato, superar todas as defasagens, não compensam as desigualdades 
sociais. Melhoramos, sem dúvida, nosso trabalho de pesquisa e de formação. Só que o que temos que fazer com e para os alunos é sempre mais difícil e complicado porque a defasagem continua a existir em benefício dos melhores. É uma coisa triste constatar que as desigualdades sociais não param de crescer na sociedade francesa. Mas como não levar em conta que a pedagogia, a formação e a pesquisa não podem eliminar nem ultrapassar sozinhas todas as injustiças sociais? No entanto, não é uma razão para desistir. Muito pelo contrário.

Nós temos uma diferença muito grande em relação à França e suas práticas culturais. Você considera possível fazer um paralelo entre a realidade dos alunos de nossas escolas públicas e aquela dos filhos de imigrantes na França, que representam a camada mais desprovida? Seria possível adotarmos aqui as políticas de leitura desenvolvidas no contexto francês, considerando as configurações das escolas públicas francesas?

Penso que podemos aprender muito considerando as experiências dos outros, se pudermos ser capaz de absorvê-las, transformá-las e configurá-las de acordo com nossas realidades locais. Claro: Só a antropofagia nos une! Sabemos que existe uma grande tradição de circulação de saberes e modelos educacionais entre o Brasil e a França. Uma pesquisa dirigida por Belmira Bueno sublinha isso e mostra ao mesmo tempo quanto precisamos nos acautelar contra o imediatismo, para considerar a ruptura, a diferença, a contextualização como problema de método. É claro que os contextos culturais e sociais, a relação histórica, as culturas da escrita são totalmente diferentes, as problemáticas da imigração também são outras. Só que se observam em ambos os países aspectos comuns, por exemplo, no que tange tanto à postura dos professores a respeito da oferta de leitura como à recepção dessas propostas pelos adolescentes, particularmente por aqueles muito afastados da cultura legítima. Tanto na França como no
Brasil, podemos observar um divórcio entre a formação dos professores do ensino médio, de cunho acentuadamente disciplinar e acadêmico, e a realidade das práticas culturais e vivências dos alunos. De certa forma, as práticas culturais dos alunos referentes à leitura não são levadas em conta de modo muito forte e evidente no ensino médio. 0 mesmo tipo de rejeição à leitura literária escolar que se observa entre os alunos brasileiros do ensino médio lembra muitas vezes as rejeições que se observam na França. Então, vale a pena considerar as leituras reais e as leituras invisíveis dos alunos, pois estamos diante de um fenômeno relacionado ao divórcio entre a oferta pedagógica e a recepção por parte dos leitores adolescentes.

Você pode falar um pouco mais sobre essas leituras invisiveis para a escola?

$\mathrm{Na}$ representação comum, ler é ler a literatura, ler livros de literatura essencialmente em suportes de papel. Muitos adolescentes não se consideram verdadeiros leitores porque apreciam pouco a literatura escolar e pouco leem as obras recomendadas ou impostas. No entanto, eles leem! Eles leem, até mesmo muito mais do que os adultos imaginam. Só que eles não leem aquilo que os adultos, sobretudo os professores, desejariam que eles lessem. Daí decorre um grande mal-entendido. Suas práticas de leitura mais correntes são invisíveis em classe e parecem não ter a menor importância. No entanto, eles leem, sobre muitos suportes, notícias, jornais, revistas. Leem e escrevem abundantemente em múltiplas telas. Alguns, em números até significativos, até leem literatura, só que não é a desejada pela escola. Os gêneros que eles amam não são legítimos no campo escolar. Ora, rejeitar essas leituras invisíveis significa rejeitar sua cultura e finalmente eles próprios. Em contrapartida, muitos deles rechaçam também os textos e os autores que à escola parecem essenciais, mas que a eles se mostram muito distantes de suas vidas e de sua língua. Essa rejeição parece 
crescente. Por isso, é preciso sair desse impasse pedagógico, porém, sem cair numa demagogia. Isso não abriria nenhuma perspectiva de desenvolvimento cultural. É preciso questionar e reduzir essa distância que existe entre a realidade dos alunos e as práticas clássicas de ensino da literatura. As formas tradicionais de transmissão do patrimônio cultural ganhariam muito se se transformassem em mediações suscetíveis de favorecer as passagens de uma leitura a outra, de uma cultura a outra. Na prática, temos que reinventar o papel e as formas de mediação, uma vez que elas poderão permitir que na escola se faça o caminho entre a cultura dos jovens, a cultura do século XXI e a cultura legítima que os professores desejam compartilhar com os alunos. Acho que é uma questão de pontes. Temos que organizar e estabelecer pontes entre essas culturas. Realizar essa tarefa é um verdadeiro desafio! 0 desafıo da democratização. Isso supõe rever a formação dos professores; supõe, por exemplo, ser capaz de propor aos alunos textos e ferramentas que se articulam com temas e questões da contemporaneidade, assim como a própria contemporaneidade da leitura. Nas salas de aula, a existência de uma literatura infanto-juvenil de boa qualidade pode permitir estabelecer essas pontes entre o texto de hoje e os textos clássicos do patrimônio nacional e mundial.

Essa questão nos remete às pesquisas que evocamos, particularmente aos trabalhos recentes sobre o lugar do sujeito leitor em didática da literatura. Na tradição escolar, a recepção dos textos pelo sujeito leitor tem pouco espaço. 0 que importa antes de mais nada é levar o aluno àquilo que consideramos como boa compreensão ou uma boa interpretação. Essa interpretação correta, na antiga tradição pedagógica, supunha identificar a intenção do autor (o que chamamos o texto do autor). Considerava-se também e, sem dúvida, considera-se ainda hoje, implicitamente, que a boa interpretação do aluno é aquela que se cola à do professor (o que chamamos de o texto do professor). Nos anos 1960, por reação, o estruturalismo quis glorificar o texto, desvinculando-o de todo aporte biográfico e histórico, declarando inclusive, com Barthes ,a "morte do autor". Durante uma determinada época, toda a atenção foi então voltada para o texto, unicamente para o texto, a fim de extrair dele redes de significação. Nos últimos tempos, os trabalhos sobre a recepção e as pesquisas em didática evidenciaram um aspecto essencial da leitura: a existência de um texto do leitor, produto da recreação original que representa toda leitura. Nessa perspectiva, o jovem leitor em formação passa do estatuto de simples receptor passivo à de ator cultural, de cocriador. Em consequência, é importante saber: como fazer aparecer o texto de cada leitor e que valor conceder a ele; como usá-lo na análise literária e na condução da aula; que fontes intelectuais, psíquicas, culturais, sociais, alimentam esse texto do leitor. Essas fontes, repousam claramente sobre a diversidade das culturas e das experiências de vida, o que supõe uma nova questão, introduzida por Catherine Tauveron: que lugar dar aos "direitos do leitor" e aos "direitos do texto"? Como não se deixar levar pelos delírios interpretativos individuais ou coletivos? E, enfım, que lugar dar ao texto do professor, à autoridade e ao saber do professor? Classicamente, supõe-se que o texto do professor ajuda o aluno a descobrir o texto, o texto do autor. 0 texto do professor teria por objetivo levar cada aluno a melhor construir seu próprio texto a partir do texto do autor. Entretanto, a análise das práticas mostra que, se o texto do professor pode guiar o aluno, não é incomum que seja um obstáculo para a aparição do texto do leitor, até finalmente impor uma leitura magistral. Por último, apontarei um questionamento decorrente da tese de Pierre Bayard: na medida em que o "texto se constitui de uma parte importante de reações individuais de todos aqueles que o encontram e o animam com sua participação", como organizar e gerir em sala de aula essa polifonia interpretativa dos leitores? Eis aí um vasto campo de pesquisa e de formação. 
Pistas pedagógicas fecundas foram abertas nesses últimos anos e se inscrevem num vasto campo de renovação da aprendizagem da leitura e do ensino da literatura, mesmo que ainda devam ser aprofundadas. Entre elas, quero citar a prática da intertextualidade, que se traduz didaticamente pela organização de leituras em redes, o debate interpretativo, os círculos de leitores - ambos susceptiveis de favorecer a emergência do sujeito leitor -, a leitura em voz alta (reconsiderada em suas funções escolares), o diário de leitura. Diretamente provenientes das pesquisas, essas proposições serão certamente retrabalhadas, redefinidas, enriquecidas nos próximos anos. Sua eficácia dependerá essencialmente da associação a uma pedagogia da compreensão, preocupada em ensinar as estratégias de leitura e ajudar os alunos a construírem os saberes culturais, cognitivos e metacognitivos indispensáveis para superar as dificuldades na leitura, no tratamento da informação e na realização de inferências tanto textuais quanto extratextuais.

Você tem falado sobre a configuração das bibliotecas, a importância da inserção e atualização das bibliotecas no mundo digital. $\mathrm{Na}$ França, os profissionais que trabalham nas bibliotecas escolares têm uma formação específica na universidade?

Sim, na universidade, nas ESPE, é oferecida uma formação em nível de mestrado para os futuros bibliotecários e documentaristas escolares que irão atuar depois em todas as escolas do ensino médio e no ensino fundamental II, uma vez que essa presença é uma obrigação institucional. Necessariamente, essa formação dos bibliotecários em cinco anos, no nível de mestrado, prepara para a gestão de informática de um centro de documentação, mas também para a formação dos leitores e o ensino do tratamento da informação. É claro que hoje em dia as bibliotecas, sem deixar de lado a promoção tradicional da cultura da escrita, têm que se reposicionar como cybercentros a serviço da informação e da formação permanente de todos. Elas têm um papel insubstituível para conjugar as antigas práticas de leitura com as novas. Na França, os professores se inspiraram bastante no modelo das bibliotecas públicas para criar as bibliotecas escolares. Um dos maiores objetivos das bibliotecas como centros documentários nas escolas era modificar a relação com o saber e o acesso à informação; tratava-se de modificar a clássica relação frontal, vertical, entre um professor e uma sala de trinta alunos, durante uma hora, um dia, um ano, muitos anos... A ideia era permitir a cada um construir seus saberes numa outra configuração, de modo mais autônomo, responsável, diferente do tradicional frente a frente aluno-professor. Hoje ainda há muito a se fazer nessa área. A revolução digital oferece muitas possibilidades, mas tudo vai depender da inserção dessas novas ferramentas no universo escolar.

Será que elas vão abrir um novo gap? 0 que estamos tentando colher ao promover acessos, meios e políticas de inclusão por meio das tecnologias é uma crença de que se pode vencer, apesar da falta de uma herança cultural. 0 fato é que $90 \%$ da população brasileira está na escola pública e esses alunos não têm herança letrada. Entretanto, eles têm acesso às tecnologias muito mais do que aos livros. Como isso se repercute na escola, principalmente no que se refere à leitura? Mais uma vez, como fica o papel da escola?

As novas tecnologias oferecem ferramentas extraordinárias para construir os saberes, sem dúvida. Mas é possível também que sejamos vítimas de novas ilusões, como foi o caso anterior, quando da aparição do audiovisual. A ferramenta é uma coisa, o domínio da mesma é outra coisa; a introdução e a inclusão dessa inovação na sala de aula é, por sua vez, uma terceira coisa. Dispor de milhares de informações na web não implica automaticamente a apropriação delas. A localização, o tratamento, a análise, os usos das fontes de informação 
demandam uma aprendizagem complicada e requerem professores capazes de acompanhar esse percurso. A leitura e a pesquisa sobre qualquer suporte necessitam de uma formação constante, ao longo de toda a escolarização. Nesse âmbito, o papel da biblioteca e o dos professores de leitura se torna essencial. Essas realidades foram aclaradas pelas últimas avaliações PISA, que, pela primeira vez, propuseram provas de leitura em monitores para avaliar as competências mobilizadas na leitura digital. Por enquanto, esse campo de formação é pouco explorado. Ainda que um movimento de interação do digital pareça estar se afirmando, ele é ainda tímido. Quando falei sobre o afastamento e a distância entre as práticas de ensino e as práticas culturais reais das crianças e jovens, referi-me também a esse aspecto da modernidade tecnológica. Uma parte importante das leituras invisiveis dos alunos é digital. Nesta época da comunicação informática e da revolução tecnológica, como poderíamos deixar de incluir essa dimensão no nosso trabalho com os alunos, já que eles nasceram nesse mundo? Entretanto, as escolas, muitas vezes, fogem desse mundo. Em muitos países, os jovens utilizam com frequência mais a informática e as tecnologias fora da escola. Ora, se essa aprendizagem dos usos se realiza e se aprofunda longe da esfera escolar, é preciso considerar que ela é também marcada socialmente. As desigualdades se mantêm vivas no que concerne às possibilidades de acesso à informação digital. Existem novas formas de analfabetismo funcional e é bem possível que os novos iletrados sejam dos mesmos meios sociais que os antigos alunos fracos, maus leitores sobre o suporte papel. Nesse campo, como em muitos outros, a escola pode contribuir para a melhoria das oportunidades e das perspectivas de cada aluno, mas sabemos que sozinha não é capaz de impor transformações radicais na estrutura e nas relações sociais. Se a sociedade continua a reproduzir desigualdades, isso vai se encontrar novamente na escola, inclusive no uso escolar das tecnologias para formar o leitor que se deseja no século XXI. Dito isso, continuo, apesar de tudo, relativamente confiante, pois, se observarmos os grandes mecanismos de nossas sociedades, em longo prazo, a educação é sempre percebida como uma engrenagem capaz de melhorar a relação com o mundo de cada um. Estou persuadido de que ela continuará a funcionar assim. E é certamente isso que dá sentido a nossos esforços.

\section{Referências}

BOURDONCLE, Raymond. Autour du mot "Universitarisation". Recherche et formation, Lyon, n. 54, 2007.

BRASIL. Ministério da Educação e do Desporto. Secretaria de Educação Fundamental. Projeto Pró-Leitura na formação do professor. Brasília, DF: MEC/SEF, 1996. 68 p.

\section{Bibliografia selecionada do autor \\ Obras e artigos do autor em português e espanhol}

BUTLEN, Max. Compreensão e interpretação literárias: duplo risco da escola ao liceu. Leitura: Teoria e Prática, Campinas, n. 58, jan./jun. 2012.

BUTLEN, Max. La lectura em la biblioteca y en la biblioteca multimídia. In: ROSING, Tania (Org.). Leitura e animação cultural: repensando a escola e a biblioteca. Passo Fundo: Universidade de Passo Fundo, 2002.

BUTLEN, Max. La lectura en la escuela y en la biblioteca: entre el poder y el deseo. Geografias Lectoras, Salamanca, p. 41-56, 2001. 
BUTLEN, Max. Las bibliotecas escolares en el sistema educativo francês. La organización de los CDI y las BCD en Francia. Conclusiones. In: SIMPOSIO DE CANARIAS SOBRE BIBLIOTECAS ESCOLARES Y ANIMACIÓN A LA LECTURA,CONSEJERÍA DE EDUCACIÓN, CULTURA Y DEPORTES, LAS PALMAS, ISLAS CANARIAS, 1, 1994, Islas Canarias. I Simposio... Islas Canarias: Gobierno de Canarias, 1994.

BUTLEN, Max. Ler, compreender e interpretar textos literários na escola. In: ROSING, Tania (Dir.) Questões de leitura. Passo Fundo: Universidade de Passo Fundo, 2003.

BUTLEN, Max. 0 desafio da participação dos profissionais de campo na formação docente. São Paulo: Unesp, 2015. No prelo.

BUTLEN, Max. Para novas cooperações entre escolas e bibliotecas: retorno aos objetivos e missões. Revista Eletrônica da Faculdade de Ciências e Tecnologia do Departamento de Educação, Presidente Prudente, 2012. Disponível em: <http:// revista.fct.unesp.br/index.php/Nuances/article/viewFile/1620/1556>. Acesso em: 2014.

BUTLEN, Max. Paradojas de la lectura escolar. Revista de Educación: Sociedad Lectora y Educación, Madrid, n. extraordinário, p. $139-153,2005$.

BUTLEN, Max. Proposta para uma política de leitura. Boletim da Associação Internacional de Leitura Conselho Brasil Sul (ALBS). International Reading Association (IRA), Porto Alegre, n. 1-2, p 3-17, 1995.

BUTLEN, Max. Réflexions sur l'offre et les politiques de lecture. Revista Educación y Biblioteca. Madrid, n. 143, 2004.

\section{Obras e artigos publicados na França e em outros países da francofonia}

AHR, Sylviane; BUTLEN, Max. Savoir lire/aimer lire: un couple en évolution ou en voie de séparation? In: ÉLALOUF, MarieLaure (Dir.). Études de linguistique appliquée: les connaissances cachées développées par la lecture et l'écriture électronique extrascolaires, éla, etudes de linguistique appliquée. Revue de Didactologie des Langues-Cultures et de Lexiculturologie, Paris, n. 166, 2012.

AHR, Sylviane; BUTLEN, Max; ELALOUF, Marie-Laure. Lecture sur écran, lectures sur papier: discours et représentations des élèves de 15 ans. Le Français Aujourd'hui: L'Enseignement des Lettres et le Numérique, Paris, n. 178, 2012.

BECCHETTI-BIZOT, Catherine; BUTLEN, Max (Dir.) L'enseignement des lettres et le numérique. Le Français Aujourd'hui: L'Enseignement des Lettres et le Numérique, Paris, n. 178, 2012.

BISHOP, Marie-France; BUTLEN, Max (Dir.). Continuité et rupture dans l'enseignement de la littérature. Le Français Aujourd'hui: L'Enseignement des Lettres et le Numérique, Paris, n. 168, 2010.

BRUNO, Pierre; BUTLEN, Max (Dir.). Genre, sexisme et féminisme. Le Français Aujourd'hui: L'Enseignement des Lettres et le Numérique, Paris, n. 163, 2008.

BRUNO, Pierre et al. Enseigner la littérature de jeunesse. Le Français Aujourd'hui: L’Enseignement des Lettres et le Numérique, Paris, n. extra, 2008.

BUTLEN, Max. De la politique de la lecture publique aux politiques publiques de la lecture. Bulletin des Bibliothèques de France: Regards sur un Demi-Siècle, n. extra, p. 45-69, 2006.

BUTLEN, Max. La lecture pratiques individuelle versus pratique sociale. Le Cri du Hibou, n. 17, automne 2012.

BUTLEN, Max. La littérature de jeunesse, un couple agité mais inséparable. In: BIBLIOTHEQUE NATIONALE DE FRANCE. Livres d'enfants d'hier et aujourd'hui. Paris: Bibliotheque Nationale de France, 2008.

BUTLEN, Max. Les politiques de lecture et leurs acteurs - 1980-2000. Lyon: Institut National de Recherche Pédagogique, 2008. 614 p.

BUTLEN, Max. Lire, analyser, sélectionner catégoriser la littérature pour la jeunesse: Quels critères? Pour quels usages? Les Cahiers de L'Association Internationale des Études Françaises, n. 66, maio 2014. 
BUTLEN, Max. Quels critères de choix des œuvres de référence en littérature dans les programmes pour l'école. In: LOUICHON, Brigitte; ROUXEL, Annie (Dir.). La littérature en corpus: documents, actes et rapports pour l'éducation. Dijon: SCEREN: CRDP de Bourgogne, 2009.

BUTLEN, Max. Tensions dans la formation enseignante entre universitarisation et professionnalisation. Administration et Éducation, Sèvres, 2015. No prelo.

BUTLEN, Max. XIIIe Rencontres des chercheurs en didactique de la littérature. [Postface]. In: AHR, Sylviane; DENIZOT, Natahlie. Les patrimoines littéraires à l'école: usages et enjeux. Diptyque: PUF de Namur, 2013.

BUTLEN, Max; CHARTIER, Anne-Marie (Dir.). Analyse de pratiques: de la recherche à la formation. Recherche et Formation, Paris, n. $51,2006$.

BUTLEN, Max; COUET, Madeleine; DESAILLY, Lucie. Savoir lire avec les BCD. Argos Démarches. Paris: CRDP de l'Académie de Créteil, 1996.

BUTLEN, Max, DUBOIS-MARCOIN, Danielle (Dir.). La littérature de jeunesse: repères, enjeux, pratiques. Le Français Aujourd'hui: L'Enseignement des Lettres et le Numérique, Paris, n. 149, 2005.

BUTLEN, Max; HOUDART-MEROT, Violaine (Dir.). Interprétation et transmission littéraire à l'école. Cergy-Pontoise: UCP: Encrage, 2012.

BUTLEN, Max; LORANT-JOLLY, A. (Dir.). Etat des lieux des recherches et des formations universitaires en littérature de jeunesse. Paris: Bibliothèque Nationale de France, 2012.

BUTLEN, Max et al. De quelques points de résistances dans la mise en place d'un enseignement de la littérature à l'école primaire. Repères, Lyon, p. 197-226, 2008.

BUTLEN, Max et al. La culture de l'écrit et les réseaux de formation. Argos Références, Paris: CRDP de l'Académie de Créteil, 1992.

BUTLEN, Max et al. Les voies de la littérature au cycle 2. Argos Demarche, Paris: CRDP, 2008. 